\title{
Solar Powered Refrigeration System with Cold Bank
}

\author{
Simson Pinto* and A. Madhusudhan \\ Department Mechanical Engineering, NMIT, Bangalore - 560064, Karnataka, India; \\ simson.pinto@gmail.com, acharyamadhusudhan@gmail.com
}

\begin{abstract}
The Storage and transportation of some goods such as vaccines, foods and other items requires cold storage. Today most of refrigerators at off-grid areas run on generators and batteries. In this context, solar refrigerator without use of battery is promising option to solve the problems. This paper describes experimental investigation of solar powered battery-free refrigerator, with use of cold thermal bank, to provide cooling at night. The refrigerator system is designed for a capacity of 150 liter. The supply of electricity to run AC compressor is provided by solar panels through the inverter. In addition to this, provision is made to work at night, by use cold thermal storage bank which provides cooling effect at night and maintains temperature by preventing thermal fluctuation caused by intermittence supply of electricity by PV panel. The solution of propylene glycol with water of 20:80 by volume is used as thermal reservoir. When the refrigerator is powered by PV panels, the solution takes $3 \frac{1}{2}$ hour to reach to reach $-100 \mathrm{C}$ with full load condition. The aqueous solution of 10 Liters can provide cooling for almost 17 hours with full load condition without running refrigerator. For domestic and small business applications, this type of solar refrigerator can be used .It can be ideal solution to store vaccines or food, which requires low temperature during transportation
\end{abstract}

Keywords: Cold Storage, Propylene Glycol, Thermal Reservoir, Vapor Compression Refrigeration System

\section{Introduction}

Refrigeration is necessary for safe storage of vaccines and other perishable goods. To achieve this operation continuous supply of electricity is essential. In most of rural or off-grid areas, electricity is mostly unavailable; hence alternate source of energy is required. In most of the grid areas, the demand of electricity excedes the supply resulting in unreliable and insufficent for continous refrigeration . This poses serious challenge for preservation of vaccines or food items. Aborption refrigeratars have been used for many years alternate to electrical refrigerators but uses, kerosene and gas to run generators, which does not meet to WHO requriments.solar powered electrical refrigeratoar is innovative soltution. Sanford et.al. investigated and compraed three types of solar refrigerators and concluded on the basis of economic and pratical viability that, photvoltaic refrigeraotrs is the ideal solution and upright one to use at off-grid areas.

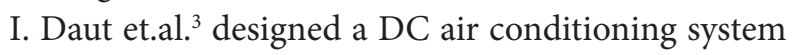

powered by photo-voltaic system. Performance of such system is strongly dependent, on cooling load, electrical equivalent and IV characteristic of the system. O. Ekren et.al. Jevaluated performance of PV-powered refrigeration. The result concluded that Overloading of the refrigerator must be avoided for better performance. Highest COP was observed at no load condition and maximum of $15.1 \%$ energy conversion is available in PV system. C. Mira-Hernánde et.al. has studied compressed energy storage for solar powered vapor compression refrigeration in residential cooling. The cooling system with thermal storage can meet the cooling load at a reasonable solar collection area. And overall efficiency of performance is comparable to alternate solar cooling system. Kapil K Samar et.al. thermodynamic and economic analyses of solar PV refrigerator of 20 liter capacity were done. The COP of the system reduced from Moring to afternoon. Average COP at full and no load condition were 3.9 and 3.29. The payback periods of the system for each $125 \mathrm{~W}$ module of three were six month.

*Author for correspondence 
Micheal K Ewert et.al. have tested PV powered battery-free refrigerator. Suggested that successful implementation of thermal storage required well insulated cabinet and PCM with high latent heat. Asmaa Ahmeed et.al. [investigated on performance on solar powered 50 liters portable refrigerator with/ without PCM thermal energy storage with/without loading in hot air condition. The result showed that PCM with full load condition the $\mathrm{COP}$ at indoor condition is higher than outdoor one. A $\mathrm{COP}$ of 1.22 and storage temperature of $5^{\circ} \mathrm{C}$ at third day is achieved and $0^{\circ} \mathrm{C}$ at sixth day. The author concluded such system can be used in remote, off-grid areas. Per Henrik Perdersen et.al.] developed solar refrigerator replacing lead batteries with ice storage cabin. The result yielded that specific cooling capacity of ice is $62 \%$ specific cooling capacity compared to lead acid battery based on weight and 13\% low volume occupation based on volume of battery. Sanjay Kumar et.al. If have experimentally analyzed 40liter solar refrigerator and monitored under Indian climate for economic and affordability feasibility. Maximum COP of $3.38 \%$ was achieved but not suitable for domestic application due high cost and long payback period. Hence battery free system has to develop for encourage domestic application.

Vincenzo La Rocca et.al. . $^{\text {I }}$ evaluated performance of vapor compression refrigeration system by replacing R22 with alternate refrigerant. Replacement of HFC's poses many economical and complex challenges as well problems since it requires retrofitting that involves replacements of different components. Substitute refrigerant gives less performance compared to HFCs. Michael Beck et.al.'2 analyzed low thermal storage for refrigeration application. The result yields strong dependence of size of the solar panel and storage size. For $30 \mathrm{~m}^{2} \mathrm{PV}$ area and 30 liters of cold storage volume for $0{ }^{\circ} \mathrm{C}$ and $-21{ }^{\circ} \mathrm{C}$, the maximum energy saving $85 \%$ compared to reference family. S.R Kalbande et.al..$^{\text {月 }}$ the results showed the average Photovoltaic efficiencies were $8.4 \%$ and $8.2 \%$ at no load and full load condition. And energy efficiencies were $11.4 \%$ and $11.2 \%$ at no load and full load condition.

The major drawback in the present system is use of batteries, which are expensive and requiring constant maintenance. Toxic lead-acid chemicals used in most of the batters leads to pollution and have to carefully handle, which becomes difficult in rural areas, hence this project replaces batteries with cold thermal storage bank. From the literature, it is possible to design a refrigeration system free from batteries can be replaced with thermal energy storage. Hence this project incorporates cold storage bank eliminating battery

\section{Methodology}

Design of solar PV-powered refrigerator, arise different challenges since, the electrical characteristic of the PV panels has to match with electrical characteristic compressor and arrangement should be made to run at night, when no electricity is available. Aqueous solution is used as cold thermal reservoir, which gives provides cooling effect at night. Also maintains the temperature of the Evaporator Cabin, caused by fluctuation of electricity due to clouds. The Figure 1 shows the outline of the project.

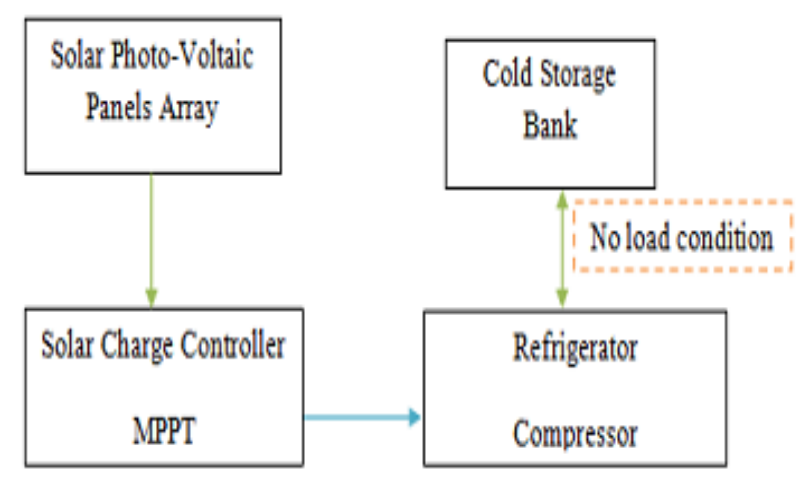

Figure 1. Outline of the project.

The refrigerator is designed like a domestic refrigerator; consist of three chambers placed over the other. The main chamber made of rectangular steel box ${ }^{\text {a }}$, where goods are stored for refrigeration. Surrounded by this cabin, cold thermal bank is placed, contains propylene glycol and distilled water in the ratio 20:80 \% by volume. Propylene Glycol liquids have high boiling and low freezing points, which permit volume storage in a wide range of climates .The temperature range required for vaccine storage is -5 to -10 . A series of experiments were conducted to know the required ratio proportion of propylene glycol and distilled water. The following Table 1 shows the experimental values .From the table is clear that required ratio is $20: 80 \%$ by volume. This ratio is chosen based on required cabin temperature i.e., $-10^{\circ} \mathrm{C}$ 
The thermal reservoir chamber is coiled around with evaporator copper tubes, wherein primary refrigerant R134a, flows and absorbs heat from both the chambers. The copper coils are wrapped by another thermally insulated chamber with polyurethane foam (PUFF) of $50 \mathrm{~mm}$ thickness, to prevent heat leakage from environment. The specification and material of the refrigerator is shown in Table 2.

Table 1. Temperature value of the propylene glycol solution

\begin{tabular}{lcccccccc}
\hline \multicolumn{7}{c}{ Freezing Point of Propylene Glycol Solution } \\
\hline $\begin{array}{l}\text { Propylene } \\
\text { Glycol }\end{array}$ & $\%$ by Volume & 0 & 10 & 20 & 30 & 40 & 50 \\
$\begin{array}{l}\text { Distilled Water } \\
\text { Freezing }\end{array}$ & $\%$ by Volume & 100 & 90 & 80 & 70 & 60 & 50 \\
Temperature & ${ }^{\circ} \mathrm{C}$ & 0 & -3 & -8 & -14 & -22 & -48 \\
\hline
\end{tabular}

\subsection{Materials and Specification}

Table 2. Components and specification of the refrigerator

\begin{tabular}{|c|c|c|}
\hline Components & Material & specification \\
\hline Primary & Stainless steel & $600 \times 300 \times 360 \mathrm{~mm}$ \\
\hline \multicolumn{3}{|l|}{ Cooling Cabin } \\
\hline Cold Storage & Stainless steel & $650 \times 350 \times 400 \mathrm{~mm}$ \\
\hline Chamber & $\begin{array}{l}\text { (chemically resistant } \\
\text { with PCM) }\end{array}$ & 20 liter capacity \\
\hline Phase Change & Propylene glycol and & $20: 80 \%$ by \\
\hline Material & distilled water & volume,10lt. \\
\hline Evaporator Tubes & Copper & $7 \mathrm{~m}$ \\
\hline Insulation & Polyurethane foam & $\begin{array}{l}\text { 10kg, } 10 \mathrm{~mm} \\
\text { chamber thickness }\end{array}$ \\
\hline Compressor & $\begin{array}{l}\text { Hermitically sealed } \\
\text { compressor }\end{array}$ & $155 \mathrm{~W}$ \\
\hline Condenser & Copper & $8 \mathrm{~m}$ \\
\hline Condenser Fan & $\begin{array}{l}\text { Company : } \\
\text { HICOOL }\end{array}$ & $45 \mathrm{~W}, 1500 \mathrm{RPM}$ \\
\hline $\begin{array}{l}\text { Solar Charge } \\
\text { Controller }\end{array}$ & $\begin{array}{l}\text { Maximum power } \\
\text { point tracking }\end{array}$ & $12 / 24 \mathrm{~V}, 40 \mathrm{~A}$ \\
\hline Solar PV Panels & $\begin{array}{l}\text { Polycrystalline } \\
\text { silicon }\end{array}$ & $\begin{array}{l}75 \mathrm{~W} \text { each unit,75 } \\
\mathrm{x} 6=450 \mathrm{~W}\end{array}$ \\
\hline
\end{tabular}

\section{Results and Discussion}

The whole unit is assembled as shown in Figure 2. The solar panels are connected to the refrigerator through MPPT controller. The cold storage unit is filled with 10 liters of the propylene glycol solution. Testing of solar refrigerator was conducted on $6^{\text {th }}$ April 2016. The sun was shiny, clear sky and ambient temperature recorded $32^{\circ} \mathrm{C}$. The refrigerator was started at $10 \mathrm{am}$ and left for running for the whole day, till the sunlight was available. In between temperature of the cabin temperature was noted. The refrigerator provided cooling effect for cabin space and cold storage solution to freeze. It took 3 and a half hour to cool down the inside chamber as well as the propylene glycol solution to a temperature of $-10^{\circ} \mathrm{C}$

The refrigerator was switched off at $4 \mathrm{pm}$ in the evening; totally the refrigerator was working for 6 hours in a day. Temperature was noted for every interval of one hour as shown in Figure 3. The next day morning at 9am the temperature was noted down by $-4^{\circ} \mathrm{C}$. It means that the cold bank provides cooling effect for almost more than 17 hours. The cold thermal storage had 10 liter of solution which could provide the cooling load management for almost holding time of 17 hours. By varying the ratio of solution as well as the quantity holding time and freezing temperature can be increased or decreased depending upon the requirement

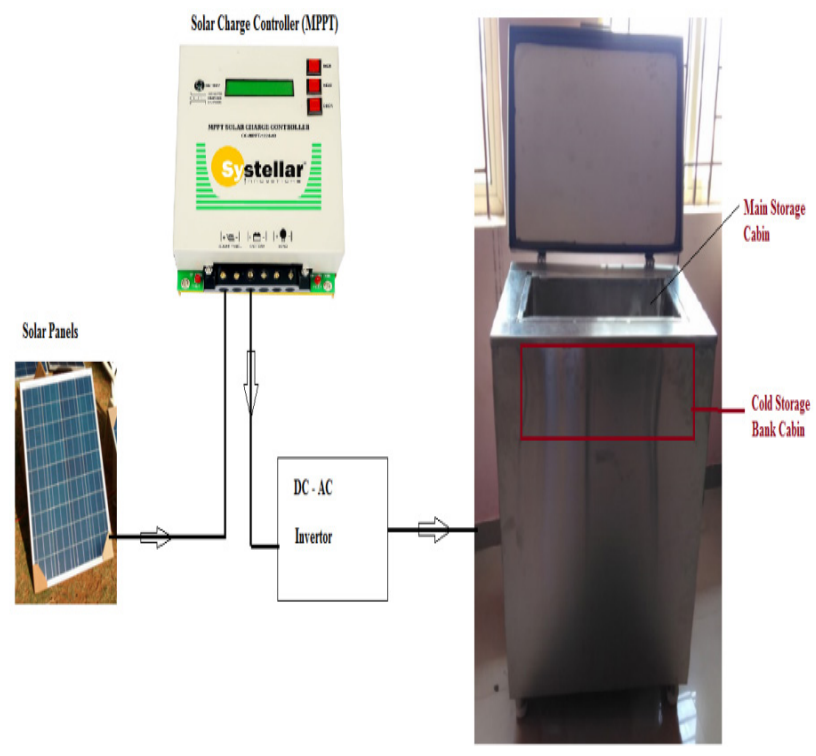

Figure 2. Assembled model of the project.

Cabin temperature was below zero for almost 16 hours which meets our requirements. The improvement in designed can be made to reduce panels' size, optimum insulation to prevent heat leakage and capacity of the compressor. The freezing temperature of the solution can be dropped further below, by increasing the ratio of the propylene glycol in the solution. The cold bank can operate for a long time if the quantity of solution used is increased. COP of the refrigerator can be enhance. 


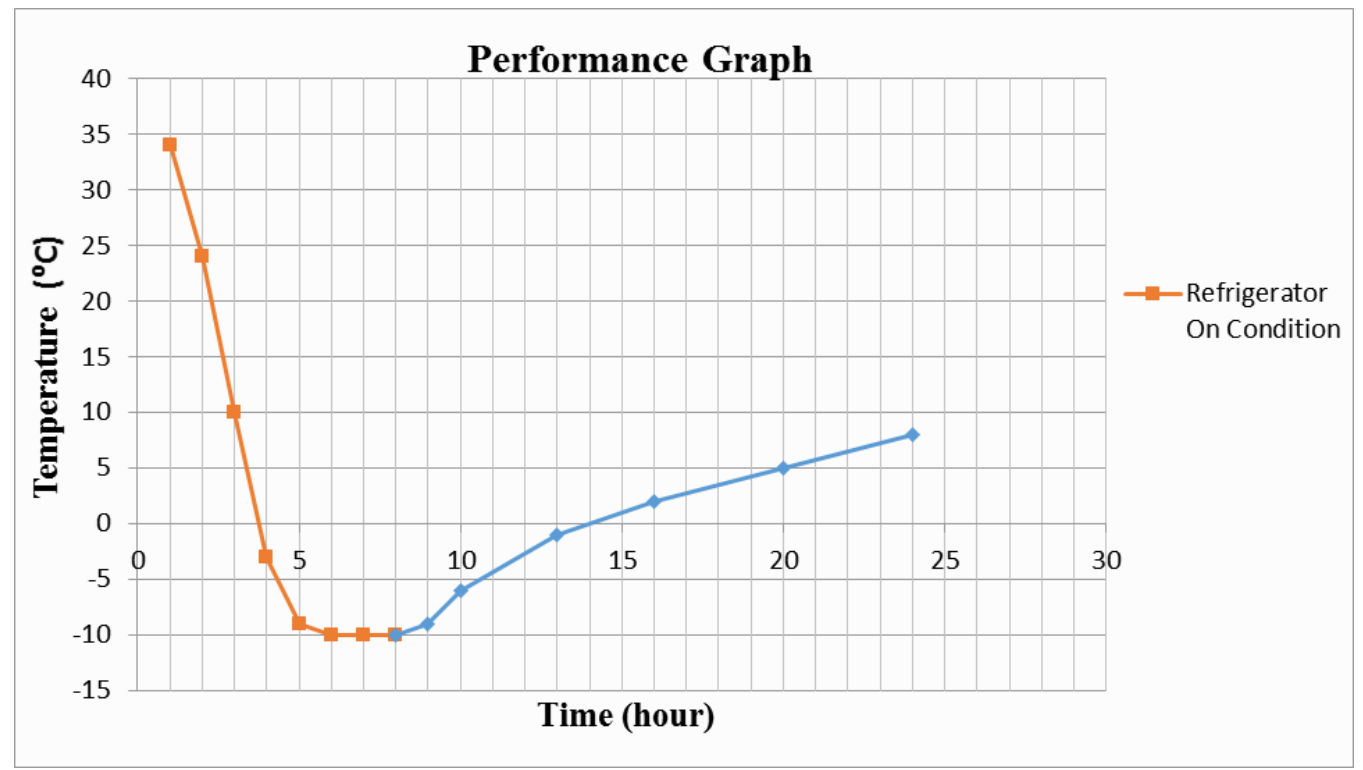

Figure 3. Performance chart of the refrigerator temperature vs. time.

\section{Conclusion}

The energy requirement of the world is increasing daily and it has become difficult to meet the demand especially in rural area where grid connectivity is unavailable. In this regard, a refrigerator is designed, with sole purpose, of running it with solar power and cold bank is provided to give cooling load at night. From the testing, it seen that, for the refrigerator of 150 liters capacity, six solar panels of $75 \mathrm{~W}$ is sufficient to run on any ordinary sunny day. The COP is the refrigerator is 1.4. It can share the load of the evaporator space and the cold thermal bank. The propylene glycol and distilled water solution in the volume ratio 20:80 can give freezing temperature of $-10^{\circ} \mathrm{C} .10$ liters of the solution can hold the cabin temperature below zero for almost 16 hours which meets our requirements. But as the loads increased the time required to reach $-100 \mathrm{C}$ was also in increased. The cooling effect of the thermal cabin can be enhanced by increasing the ratio of propylene glycol in the solution.

\section{Reference}

1. Stanford A Klein, Douglas T Reindl. Solar Refrigeration. American Society of Heating, Refrigeration and Air-Conditioning. 2005 Sep; 47(9):526-30.
2. Fong KF, Lee CK, Chow TT. Improvement of Solar-Electric Compression System through Ejector Assisted Vapor Compression Chiller for Space Conditioning in Sub-tropical Climate, Hong-Kong, China, Science Direct. 2011 Dec; 43(12):3383-90.

3. Micheal Beck. Storing Surplus Solar Energy in Low Temperature Thermal storage for Refrigeration Applicatons. Erlangn, Germany: Science Direct, 2016 Apr; 122:0378-7788

4. Xiaohong Yin, Shaoyuan, Wenjian Cai. Enhanced-effiecieny Operating Varaibles Selection for Vapor Compression Cycle System, Elsevier. 2015; 80:1-14.

5. Steven McCarney, Joanie Robertsonm, Juliette Arnaud, Kristena Lorenson, John Lloyd. Using Solar Powered Refrigeration for Vaccine Storage where other sources of reliable Electricity are inadequate or costly. Elsevier, 2013; 31:6050-57.

6. Sneha D Deshmkh, Kalbande SR, Khambalkar VP. An Environmental Impact Assessment of Photvolatic Driven Refrigeration Units. International Journal of Research in Engineering, Science and Technology. 2016; 1(6):2454-5392

7. Kalbande SR, Sneha Deshmukh. Photo-Voltaic Compression Refrigeration System for Vaccine Preservation, Universal Journal of Engineering Science. 2015; 3(2):17-23.

8. Ekren O, Yilanci A, Cetan E, Ozturk HK. Experimental Performance Evaluation of a PV-Powered Refrigeration System, Electronics and Electrical Engineering. 2011; 8(144):1392-1215.

9. Kapil K Samar, Kothari S, Jindal S. Thermodynamic and Economic Analysis of Solar Photo-voltaic operated Vapor Compressor Refrigeration System.2014 Oct; 7(2):352-59

10. Michael K Ewert, David J Bergeron, Robert E Foster, Oral LaFleur. Photo-voltaic Direct-Drive, Battery-Free Solar Refrigerator Field Test Results, Research Gate, 2002 Jun. 
11. Per Henrik Pederson, Søren Poulsen, Ivan Katic. Solarchill A solar PV Refrigerator Without Battery, Danish Technology Institute. Available from: http://www.solarchill.org/wp-content/uploads/2014/02/Eurosun2004_paper_254.pdf

12. Sanjay Kumar A Borikar, Uday S Wankhende. Experimental Analysis of Solar Refrigeration System. International Refrigeration and Air Conditioning, Purdue University, Purdue e-Pubs, Paper 999, 2008, p. 1-8
13. Tassou SA, De-Lille G, Ge YT. Food Transport RefrigerationApproaches to reduce energy consumption and environmental impacts of road transport, Elsevier. 2009; 29:1467-77

14. Vincenzo La Rocca, Giuseppe Panna. Experimental Performance Evaluation of a Vapor Compression Refrigeration plant when replacing R22 with alternate refrigerant. Elsevier. 2011; 88:2809-15. 